\title{
openheart Incremental role of CT coronary angiography in the assessment of left ventricular diastolic function
}

\author{
Aleksandra Lange (D), Harry Huntress, Jesse Steindl, Przemyslaw Palka
}

To cite: Lange A, Huntress $\mathrm{H}$, Steindl J, et al. Incremental role of CT coronary angiography in the assessment of left ventricular diastolic function. Open Heart 2021;8:e001566. doi:10.1136/

openhrt-2020-001566

Received 29 December 2020 Revised 24 February 2021 Accepted 24 February 2021
Check for updates

(C) Author(s) (or their employer(s)) 2021. Re-use permitted under CC BY-NC. No commercial re-use. See rights and permissions. Published by BMJ.

Queensland Cardiovascular Group, Wesley Medical Research Limited, St Andrew's War Memorial Hospital, Brisbane, Queensland, Australia

Correspondence to Dr Aleksandra Lange; aleksandral@qcg.com.au

\section{ABSTRACT}

Objective To determine whether Computed Tomography (CT) coronary angiography (CTCA) has clinical value for the assessment of left ventricular (LV) diastolic dysfunction (DD) beyond traditional information on coronary artery anatomy.

Method In this retrospective study, a consecutive group of 72 patients (mean age $59 \pm 13$ years) - who met the eligibility criteria of sinus rhythm, no significant valvular abnormalities, and who had transthoracic echocardiogram (TTE) — were analysed. The CTCA was prospectively triggered during diastole. Outcomes of interest were CTCA derived LV and left atrial (LA) volumes, diastolic expansion (DE) index: LV volume $\div$ LA volume and $D E$ fraction (DEF): [(LV volume-LA volume) $\div$ LV volume $] \times 100$. TTE-LA volume was measured as maximum, minimum and pre-A. Studied patients were divided according to the current classification of LVDD as a reference standard. A small subgroup of nine patients underwent further invasive cardiac catheterisation.

Results CTCA-LV and LA volumes were larger compared with TTE, $37 \% \pm 20 \%$ and $11 \% \pm 21 \%$, respectively. CTCA-LA volume correlated well with all TTE-LA volumes (maximum: $\mathrm{R}^{2}=0.58$; pre-A wave: $\mathrm{R}^{2}=0.39$; minimum: $\left.R^{2}=0.26 ; p<0.0001\right)$ with the smallest differences in maximum LA volume $(9 \pm 32 \mathrm{~mL}$; mean $\pm 2 \mathrm{SD})$. The $\mathrm{DE}$ and DEF correlated with both LA function and LVDD. DE $>1.65$ and DE $<1.40$ have good specificity ( $85 \%$ and $88 \%$, respectively), and positive predictive value to differentiate LVDD. DE and DEF were dependent on the patients' age but independent of other variables.

Conclusions CTCA derived diastasis volume indices can provide additional quantifiable information on LVDD.

Over the last two decades a great deal of progress has been achieved in refining imaging techniques in order to improve the diagnosis of coronary artery disease (CAD). CT coronary angiography (CA) is considered as the first choice test in patients with suspected CAD and intermediate pretest probability. ${ }^{1-7}$ It has the potential to reliably exclude obstructive $\mathrm{CAD}^{89}$ while halving the events of coronary heart disease after 5 years of follow-up and improving the diagnostic yield of $\mathrm{CA}^{5}$

Volumetric analysis of either atrial ${ }^{7-11}$ or ventricular size and function ${ }^{12-14}$ using

\section{Key questions}

What is already known about this subject?

- CT coronary angiography (CA) is considered as the first choice test in patients with chest pain and intermediate pretest probability. It has the potential to reliably exclude obstructive coronary artery disease.

What does this study add?

- This study proposes a new index that may assist in detection of left ventricular diastolic dysfunction and thus, refine risk stratification in patients undergoing CTCA.

How might this impact on clinical practice?

- This new index obtained from routine CTCA may add to the growing list of noncoronary applications of cardiac CT. Such an incremental prognostic value index may potentially translate into more relevant information and as a result improve the management and the prognosis.

retrospective gating CT acquisition, were reported as accurate. Since the data of prospective ECG CT triggering in the measurement of left ventricular (LV) volume is acquired at a predefined phase of the cardiac cycle, there is little information on the use of this protocol as the results need to be modified in order to estimate standard measurement of end-diastolic values. ${ }^{14}$

The availability of information on the potential role of cardiac CT in the assessment of LV diastolic dysfunction (DD) ${ }^{15-17}$ is low. Reports to date used retrospective ECG gating for the acquisition of a full cardiac cycle data which inherently has higher radiation doses. These reports provide novel insights by assessing LVDD at the same time as assessing $\mathrm{CAD}$, further evolving cardiac CT towards a more comprehensive technique in cardiovascular function assessment. The use of prospective ECG triggering reduces the radiation dose but also limits data acquisition to a particular phase of a cardiac cycleeither systolic or diastolic. It has been shown that in patients without tachyarrhythmia, 


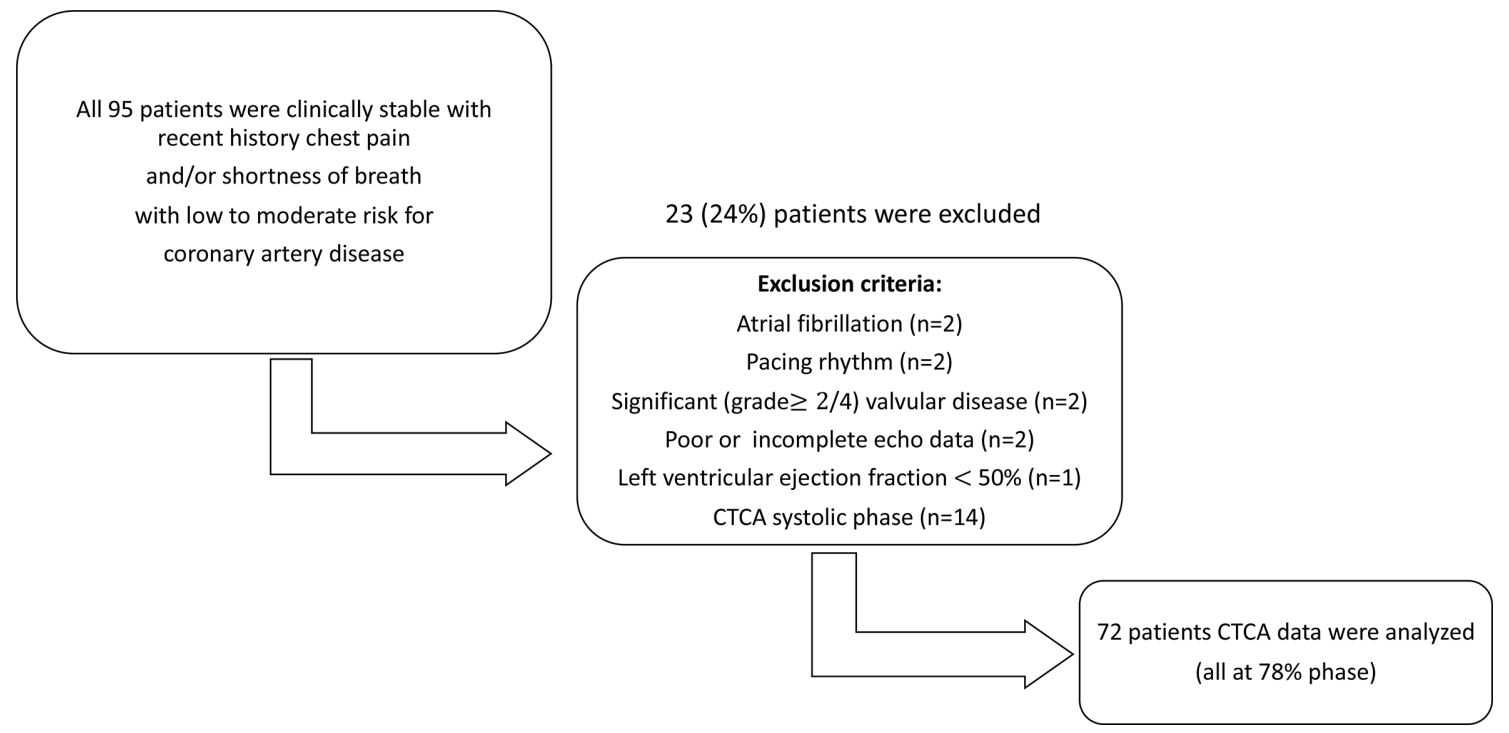

Figure 1 Patient selection criteria. CTCA, CT coronary angiogram.

prospectively triggered CTCA provides image quality and diagnostic accuracy comparable with retrospectively gated cardiac CT. ${ }^{18} 19$

The aim was to evaluate whether CTCA derived information acquired from routine prospective ECG triggered image acquisition is useful in distinguishing patients with, and without, LVDD as supported by the reference of transthoracic echocardiogram (TTE), and a small group of patients in whom catheterisation data were available.

\section{METHODS}

\section{Patient and public involvement}

The patients studied were referred for a CTCA to the Queensland Cardiovascular Group at St. Andrew's War Memorial Hospital (AL and PP), Brisbane, Australia-an expert tertiary referral centre for CAD patients-from June 2019 until November 2019. All patients have given informed written consent for their clinical data to be used in the study. Patients were not involved in either the design or the conduct of the study.

\section{Patient selection}

Patients with chest pain presentation and low-moderate probability of CAD were chosen from our clinical referral cohort if they met the following selection criteria ${ }^{1}$ : sinus rhythm, ${ }^{2}$ absence of valvopathy $\geq 2 / 4,{ }^{3}$ availability of CTCA and TTE of diagnostic image quality (figure 1, table 1). Patients with LV ejection fraction (LVEF) $<50 \%$, pacing, unstable angina or history of obstructive $\mathrm{CAD}$, coronary revascularisation, myocardial infarction or coronary artery bypass surgery were excluded. We further excluded patients with incomplete TTE data. As a result, 23 patients (24\%) were excluded from the original cohort of 95 patients. Seventy-two patients were included for further analysis. The female subgroup consisted of 38 patients $(53 \%)$. The mean age of study group was $59 \pm 13$ years. The average heart rate was $56 \pm 6$ beats $/ \mathrm{min}$ for CTCA and $70 \pm 11$ for TTE.
A group of 9 out of 72 patients underwent invasive CA. The results confirmed that $4 / 9$ patients had obstructive CA. Therefore, it is fair to assume that they must have had elevated LV end-diastolic filling pressure. LV end-diastolic pressure was measured as elevated in the remaining five out of nine patients. Therefore, it is assumed that all nine patients had elevated LV filling pressures.

Time difference between CTCA and TTE was 16 \pm 24 days (mean $\pm \mathrm{SD})$. The data was collected retrospectively.

We followed the STARD (Standards for Reporting of Diagnostic Accuracy Studies) guidance for conducting and reporting quality.

\section{SCANNING METHOD}

CTCA was acquired in a standard manner using 256iCT Philips scanner (Philips North America Corporation, Andover, Massachusetts).

An injection of iodinated contrast media (Omnipaque 350 ) was used to opacify the coronary arteries and subsequently the LA and the LV. A contrast bolus of 75-100 $\mathrm{mL}$ was injected at a rate of $5-6 \mathrm{~mL} / \mathrm{s}$ according to standard protocol. Scanning was initialised when the region of interest reached above $200 \mathrm{HU}$. The scan was acquired during a single breath-hold. The Z-axis scan range had a border of the pulmonary artery bifurcation superiorly and the inferior border of the heart inferiorly.

The iCT has $270 \mathrm{~ms}$ gantry rotation time and a temporal resolution of $135 \mathrm{~ms}$. Scan parameters were $128 \times 0.625$ mm collimation. Philip's Iterative Reconstruction algorithm, Iterative Model Reconstruction, was applied to the datasets allowing conservation of dose. $\mathrm{kV}$ and effective $\mathrm{mAs}$ were manually selected. Patients with a body mass index (BMI) $<30$ were scanned with a $100 \mathrm{kV}$ technique while those with BMI $>30$ were scanned with a $120 \mathrm{kV}$ technique. Only patients scanned in diastasis between $75 \%$ and $81 \%$ of the R-R interval were chosen for the 
Table 1 Patient demographics

\begin{tabular}{|c|c|c|c|c|}
\hline \multirow[b]{2}{*}{ Mean \pm SD or number (\%) } & \multicolumn{3}{|c|}{$\begin{array}{l}\text { Left ventricular } \\
\text { diastolic function }\end{array}$} & \multirow[b]{2}{*}{ All } \\
\hline & Normal & Abnormal & Indeterminate & \\
\hline Age (years) & $56 \pm 12$ & $65 \pm 11^{*}$ & $59 \pm 14$ & $59 \pm 13$ \\
\hline Female & $21(50 \%)$ & $12(60 \%)$ & $5(50 \%)$ & $38(53 \%)$ \\
\hline \multicolumn{5}{|l|}{ Blood pressure $(\mathrm{mm} \mathrm{Hg})$} \\
\hline Systolic & $128 \pm 13$ & $131 \pm 9$ & $122 \pm 9$ & $128 \pm 12$ \\
\hline Diastolic & $76 \pm 9$ & $76 \pm 6$ & $73 \pm 7$ & $76 \pm 9$ \\
\hline \multicolumn{5}{|l|}{$\begin{array}{l}\text { Heart rate } \\
\text { (beats/min) }\end{array}$} \\
\hline CTCA & $56 \pm 6 \dagger$ & $57 \pm 7 \dagger$ & $58 \pm 4 \dagger$ & $56 \pm 6 \dagger$ \\
\hline TTE & $71 \pm 12$ & $69 \pm 11$ & $69 \pm 9$ & $70 \pm 11$ \\
\hline \multicolumn{5}{|l|}{ Risk factors for CAD } \\
\hline Family history & $34(81 \%)$ & $17(85 \%)$ & $8(80 \%)$ & $59(82 \%)$ \\
\hline Hypertension & $23(55 \%)$ & $15(75 \%)$ & $5(50 \%)$ & $43(60 \%)$ \\
\hline Type II diabetes & $5(12 \%)$ & $7(35 \%)$ & 0 & $12(17 \%)$ \\
\hline Active smoking & $7(17 \%)$ & $4(20 \%)$ & 0 & $11(15 \%)$ \\
\hline Hyperlipidaemia & $28(67 \%)$ & $17(85 \%)$ & $8(80 \%)$ & $53(74 \%)$ \\
\hline $\begin{array}{l}\text { Total cholesterol } \\
(\mathrm{mmol} / \mathrm{L})\end{array}$ & $4.9 \pm 0.8$ & $5.2 \pm 1.1$ & $5.9 \pm 1.8$ & $5.1 \pm 1.1$ \\
\hline $\begin{array}{l}\text { HDL level } \\
\text { (mmol/L) }\end{array}$ & $1.3 \pm 0.4$ & $1.5 \pm 0.4$ & $1.4 \pm 0.4$ & $1.4 \pm 0.4$ \\
\hline $\begin{array}{l}\text { LDL level } \\
\text { (mmol/L) }\end{array}$ & $2.8 \pm 0.9$ & $3.0 \pm 0.9$ & $2.9 \pm 1.0$ & $2.9 \pm 1.0$ \\
\hline Body surface area $\left(\mathrm{m}^{2}\right)$ & $1.93 \pm 0.25$ & $1.93 \pm 0.29$ & $1.74 \pm 0.22$ & $1.90 \pm 0.27$ \\
\hline \multicolumn{5}{|l|}{ Presence of CAD } \\
\hline Normal to minimal & $20(48 \%)$ & $11(55 \%)$ & $6(60 \%)$ & $34(47 \%)$ \\
\hline Mild disease & $20(48 \%)$ & $4(20 \%)$ & $3(30 \%)$ & $30(42 \%)$ \\
\hline Moderate and/or severe & $2(5 \%)$ & $5(25 \%)^{*}$ & $1(10 \%)$ & $8(11 \%)$ \\
\hline \multicolumn{5}{|l|}{ Medications } \\
\hline Calcium channel blockers & $5(12 \%)$ & $4(20 \%)$ & $1(10 \%)$ & $10(14 \%)$ \\
\hline Beta blockers & $9(21 \%)$ & $3(15 \%)$ & $4(40 \%)$ & $16(22 \%)$ \\
\hline $\begin{array}{l}\text { ACE } \\
\text { inhibitors } \\
\text { or angiotensin II }\end{array}$ & $10(24 \%)$ & $11(55 \%)$ & $3(30 \%)$ & $24(33 \%)$ \\
\hline $\begin{array}{l}\text { Diuretics } \\
\text { (thiazides or aldosterone antagonists) } \dagger\end{array}$ & $5(12 \%)$ & $4(20 \%)$ & 0 & $9(13 \%)$ \\
\hline Vasodilators (alpha-blockers or nitrates) & $1(2 \%)$ & $2(10 \%)$ & 0 & $3(4 \%)$ \\
\hline Statins & $17(40 \%)$ & $12(60 \%)$ & $5(50 \%)$ & $34(47 \%)$ \\
\hline Oral diabetic medications & $2(5 \%)$ & $2(10 \%)$ & 0 & $4(6 \%)$ \\
\hline
\end{tabular}

${ }^{*} \mathrm{P}<0.05$ (abnormal vs normal diastolic left ventricular function).

$\dagger P<0.05$ (CTCA vs TTE corresponding data). None of the patients were on loop diuretics, and/or SGLT-2 inhibitors.

CAD, coronary artery disease; CTCA, CT coronary angiography; HDL, high density lipoprotein; LDL, low density lipoprotein; TTE, transthoracic echocardiogram.

analysis with the standard acquisition occurring at $78 \%$ (figure 2).

Patients with heart rates $\geq 65 / \mathrm{min}$ were given $50 \mathrm{mg}$ of atenolol in a single dose, or $100 \mathrm{mg}$ in two divided doses orally (unless contraindicated). All patients receive sublingual nitroglycerin before CTCA.

LA volume was measured with exclusion for the LA appendage by two expert readers who were blinded to
TTE results. LV volume was measured using an automated algorithm.

CTCA diastolic function assessment-the diastolic expansion (DE) was measured as ratio between LV and LA volume. The DE fraction (DEF) was measured as: [(LV volume-LA volume $) \div \mathrm{LV}$ volume $] \times 100$.

TTE was acquired using commercially available equipment Phillips EPIQ CVx (Philips North America 


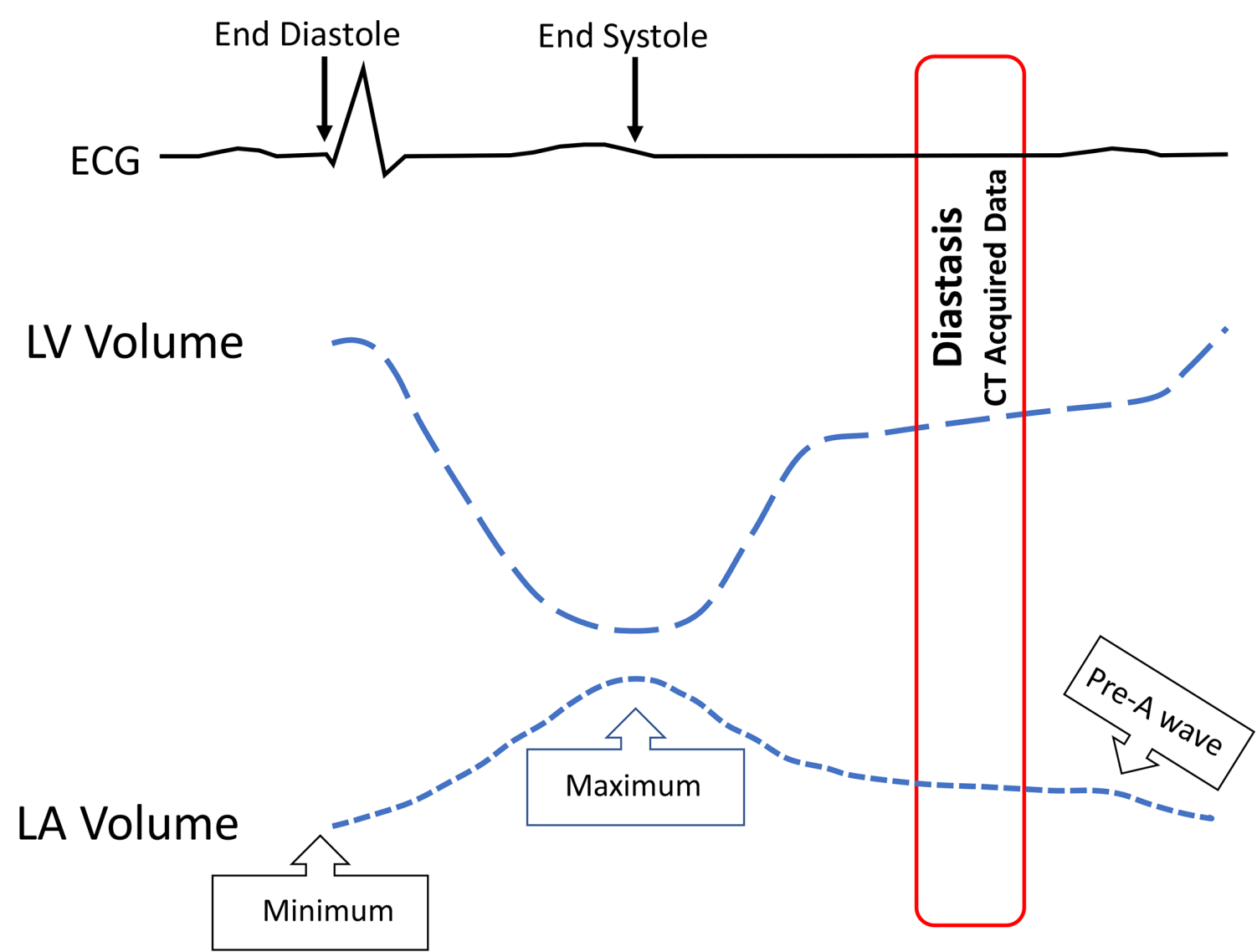

Figure 2 Schematic diagram illustrating CT coronary angiogram data capture during a cardiac cycle. LA, left atrium; LV, left ventricle.

Corporation) or Siemens SC200 (Siemens Medical Solutions, Mountain View, California, USA). Standard clinical imaging protocol was applied in each patient. The protocol consisted of M-mode, two-dimensional and Doppler analysis. Apical views were optimised to avoid foreshortening of the LA. The LA area was planimetered from the 4-chamber and the 2-chamber view, excluding the LA appendage and the pulmonary veins. Subsequent LA volumes were calculated using the biplane method. ${ }^{20}$ LA volume was measured in three phases of the cardiac cycle: maximum (at LV end-systole), minimum (at LV end-diastole) and pre-A (immediately before atrial contraction pre-P wave in ECG) (figure 2). Each measurement was averaged from three cardiac cycles. All study patients were divided according to American Society of Echocardiography/European Association of Cardiovascular Imaging recommendations for the classification of LV diastolic dysfunction. ${ }^{21}$ Since all patients had normal LVEF, the following criteria were taken into evaluation: average $\mathrm{E} / \mathrm{e}^{\prime}$, both septal and lateral $\mathrm{e}^{\prime}$ velocities, tricuspid regurgitation velocity and LA volume index.

These criteria split the patients into three subgroups showing LV diastolic function. In the indeterminate subgroup, if the difference in pulmonary venous flow atrial reversal duration to mitral inflow A wave duration was more than $30 \mathrm{~ms}$, the data were used as a marker of DD and elevated LV filling pressure. ${ }^{22}$
Table 2 shows TTE derived LA function analysis. Total, passive and active emptying volumes and fractions were calculated from TTE data according to Blume $e t a l^{23}$ with a proposed additional new index of conduit ratio where LV stroke volume is being divided by the difference between the maximum and the minimum LA volume. LA expansion index was calculated according to Thomas $e t$ $a l^{24}$

\section{Statistical analysis}

Continuous variables are expressed as mean $\pm \mathrm{SD}$, and were compared using the t-test. Categorical variables are expressed as percentages. LV, LA volumes and DE, DEF by CTCA and TTE measurements were assessed using Pearson's correlation. One-way analysis of variance (ANOVA) was used to determine differences in CTCA derived diastolic volume measurements and TTE derived diastolic function. The agreement between CTCA LA diastolic volume and TTE maximum, pre-A and minimum volume was calculated using Bland-Altman's plots. Multiple regression analysis was used to determine the contribution of anthropometric and TTE parameters for DE and DEF. Sensitivity, specificity, positive and negative predictive values were calculated in standard manner. For all analyses, $\mathrm{p}$ values $<0.05$ were considered statistically significant. The statistical analysis was performed using commercially available software (JMP V.15; SAS Institute). 
Table 2 (A) Transthoracic echocardiogram (TTE) assessment of left atrial (LA) function; (B) CT coronary angiography (CTCA) derived measurements for left ventricle (LV) diastolic dysfunction (DD)

\begin{tabular}{|c|c|}
\hline A. TTE* & Formulas \\
\hline \multicolumn{2}{|l|}{ LA pump (booster) function } \\
\hline LA active emptying volume & Pre-A-minimum LA volume \\
\hline LA active emptying fraction & $\begin{array}{l}\text { (Pre-A-minimum LA volume) } \div \text { pre-A LA } \\
\text { volume }\end{array}$ \\
\hline \multicolumn{2}{|l|}{ LA conduit function } \\
\hline $\begin{array}{l}\text { LA passive emptying } \\
\text { volume }\end{array}$ & Maximum-pre-A LA volume \\
\hline $\begin{array}{l}\text { LA passive emptying } \\
\text { fraction }\end{array}$ & $\begin{array}{l}\text { (Maximum-pre-A LA volume) } \div \text { maximum } \\
\text { LA volume }\end{array}$ \\
\hline \multicolumn{2}{|l|}{ Conduit } \\
\hline $\begin{array}{l}\text { 1. Volume } \\
\text { 2. Ratio }\end{array}$ & $\begin{array}{l}\text { 1. LV stroke volume-(maximum- } \\
\text { minimum LA volume) } \\
\text { 2. LV stroke volume } \div \text { (maximum- } \\
\text { minimum LA volume) }\end{array}$ \\
\hline \multicolumn{2}{|l|}{ LA reservoir function } \\
\hline LA total emptying volume & Maximum-minimum LA volume \\
\hline LA total emptying fraction & $\begin{array}{l}\text { (Maximum-minimum LA } \\
\text { volume) } \div \text { maximum LA volume }\end{array}$ \\
\hline LA expansion index† & $\begin{array}{l}\text { (Maximum-minimum LA } \\
\text { volume) } \div \text { minimum LA volume }\end{array}$ \\
\hline B. CTCA (new formulas) & $\begin{array}{l}\text { All measurements were acquired at } 78 \% \\
\text { phase }\end{array}$ \\
\hline $\begin{array}{l}\text { Diastolic expansion (DE) } \\
\text { index }\end{array}$ & LV volume $\div$ LA volume \\
\hline $\begin{array}{l}\text { Diastolic expansion fraction } \\
\text { (DEF) }\end{array}$ & $\begin{array}{l}((\mathrm{LV} \text { volume}-\mathrm{LA} \text { volume }) \div \mathrm{LV} \\
\text { volume }) \times 100\end{array}$ \\
\hline
\end{tabular}

*As per Blume et al. ${ }^{23}$

$\dagger$ As per Thomas et $\left.a\right|^{24}$ with modifications for conduit ratio.

Interobserver and intraobserver agreement was assessed in 28 randomly selected patients.

\section{RESULTS}

Table 3 presents TTE data.

CTCA derived volumes of both the LV and the LA were significantly larger compared with those obtained from TTE. CTCA derived LV volume was on average $37 \% \pm 20 \%$ bigger than that measured from TTE $(40 \pm 23$ $\mathrm{mL}$ for absolute values and $21 \pm 11 \mathrm{~mL} / \mathrm{m}^{2}$ for indexed volumes). There was a good correlation between those measurements $\left(\mathrm{R}^{2}=0.58 ; \mathrm{p}<0.001\right)$. This was consistent for both absolute measurements $(128 \pm 35 \mathrm{~mL}$ vs $95 \pm 28$ $\mathrm{mL} ; \mathrm{p}<0.001)$ and for indexed measurements $(67 \pm 14$ $\mathrm{mL} / \mathrm{m}^{2}$ vs $49 \pm 11 \mathrm{~mL} / \mathrm{m}^{2}$; $\left.\mathrm{p}<0.01\right)$.

CTCA derived LA volumes were larger than the TTE maximum LA volumes for both absolute measurements $(81 \pm 21 \mathrm{~mL}$ vs $72 \pm 25 \mathrm{~mL} ; \mathrm{p}<0.01)$ and for indexed measurements $\left(43 \pm 9 \mathrm{~mL} / \mathrm{m}^{2}\right.$ vs $\left.38 \pm 12 \mathrm{~mL} / \mathrm{m}^{2} ; \mathrm{p}<0.01\right)$. CTCA derived LA diastolic volume correlated well with all TTE derived diastolic LA volumes: for maximum LA volume, $\mathrm{R}^{2}=0.58 ; \mathrm{p}<0.001$, for LA pre-A volume, $\mathrm{R}^{2}=0.39 ; \mathrm{p}<0.001$, and for $\mathrm{LA}$ minimal volume $\mathrm{R}^{2}=0.26 ; \mathrm{p}<0.001$ (figure $3 \mathrm{~A}-\mathrm{C}$ ). The smallest differences in volume measurements were found between CTCA LA volume and TTE maximum LA volume (figure 3D-F). The mean difference between CTCA LA volume and TTE maximum LA volume was $9 \pm 16 \mathrm{~mL}$ and $5 \pm 9 \mathrm{~mL} / \mathrm{m}^{2}$, for absolute and indexed measurements, respectively. The average percentage of difference was $11 \% \pm 21 \%$.

TTE LA function analysis and CT derived DE and DEF are presented in table 4.

The DE and DEF correlated with the following TTE LA function indices: (i) for LA pump (booster) function: LA active emptying volume, (ii) for LA conduit function: LA passive emptying fraction, for conduit: ratio and (iii) for LA reservoir: total emptying fraction and LA expansion index. The best but weak correlation was between DEF and LA active emptying volume $\left(\mathrm{R}^{2}=0.19, \mathrm{p}<0.0001\right)$.

Table 5 summarises the comparison between CTCA derived data in all three subgroups of patients divided according to their diastolic function result: normal $(n=42$, $58 \%)$, LVDD $(n=20,28 \%)$ and indeterminate $(n=10,14 \%)$. Analysing CTCA data, patients with normal LV diastolic function had bigger: LV diastolic volumes (absolute and indexed for body surface area), LA volume indices (adjusted for body surfaced area but not absolute). Additionally, DE and DEF values were significantly higher in patients with normal LV diastolic function as opposed to those with either abnormal or indeterminate diastolic function (figure 4A-D).

$\mathrm{DE}$ and DEF decreased independently according to LVDD and increasing age (table 6). The difference in heart rate, and the time delay between TTE and CTCA measurements were not contributing to DE or DEF.

Among all CTCA diastolic volumes measurements only DE allowed to differentiate normal from abnormal LV diastolic function. The DE value above 1.65 has $85 \%$ specificity $(95 \%$ CI 0.69 to 1.01 ) and $88 \%$ positive predictive value (95\% CI 0.75 to 1.01 ) for the diagnosis of normal LV diastolic function. DE value below 1.40 has $88 \%$ specificity (95\% CI 0.78 to 0.98 ) and $62 \%$ positive predictive value (95\% CI 0.35 to 0.88 ) to diagnose abnormal LV diastolic function (table 7A).

DE markers above 1.65 and below 1.40 were also noted to differentiate normal from indeterminate LV diastolic function (table 7B) and normal from both indeterminate and abnormal LV diastolic function (table 7B,C).

As previously discussed, the presence of elevated LV diastolic pressure was confirmed in nine patients based on invasive CA. The measured range was $16-49 \mathrm{~mm} \mathrm{Hg}$, mean $25 \pm 13 \mathrm{~mm} \mathrm{Hg}$. This group of patients had lower DE and DEF $(1.37 \pm 0.18$ vs $1.79 \pm 0.45$ and $26 \pm 10$ vs $41 \pm 13$, $\mathrm{p}<0.01$, respectively). There were no significant changes in either LA volume or LA volume index $(81 \pm 21 \mathrm{~mL}$ vs $79 \pm 22 \mathrm{~mL}$ and $45 \pm 11 \mathrm{~mL} / \mathrm{m}^{2}$ vs $41 \pm 9 \mathrm{~mL} / \mathrm{m}^{2}, \mathrm{p}=\mathrm{NS}$, respectively).

\section{Interobserver and intraobserver agreement}

The agreement in CT LA volume measurements was assessed in 28 randomly selected patients with a mean LA volume of $88 \pm 26 \mathrm{~mL}$. The mean difference between 
Table 3 Transthoracic echocardiogram (TTE) data

\begin{tabular}{|c|c|c|c|c|c|}
\hline \multirow[b]{2}{*}{ Mean \pm SD or number $(\%)$} & \multicolumn{3}{|c|}{ LV diastolic function } & \multirow[b]{2}{*}{ All } & \multirow[b]{2}{*}{ Indexed } \\
\hline & Normal & Abnormal & Indeterminate & & \\
\hline \multicolumn{6}{|c|}{ TTE parameters used for the assessment of LV diastolic function } \\
\hline Maximum LA volume (mL, mL/m²) & $67 \pm 25^{\star}$ & $80 \pm 25$ & $78 \pm 25$ & $72 \pm 25$ & $38 \pm 12$ \\
\hline $\mathrm{e}^{\prime}$ septal $(\mathrm{cm} / \mathrm{s})$ & $8.0 \pm 2.3^{*}$ & $6.0 \pm 2.0$ & $5.9 \pm 2.0$ & $7.1 \pm 2.4$ & \\
\hline $\mathrm{e}^{\prime}$ lateral $(\mathrm{cm} / \mathrm{s})$ & $10.2 \pm 3.8^{*}$ & $8.2 \pm 2.9$ & $6.8 \pm 2.0$ & $9.2 \pm 3.6$ & \\
\hline Average E/e' ratio & $7 \pm 2^{*}$ & $11 \pm 6$ & $13 \pm 2$ & $10 \pm 4$ & \\
\hline $\begin{array}{l}\text { Pulmonary hypertension } \\
\text { (tricuspid regurgitation }>2.8 \mathrm{~m} / \mathrm{s} \text { ) }\end{array}$ & 0 & $\begin{array}{l}5(25 \%) \\
47 \pm 8\end{array}$ & 0 & $5(7 \%)$ & \\
\hline A wave-atrial reversal duration (ms) & $19 \pm 48^{*}$ & $-16 \pm 29$ & $9 \pm 7$ & $4 \pm 42$ & \\
\hline \multicolumn{6}{|l|}{ Other TTE parameters } \\
\hline LV end diastolic diameter (cm) & $4.4 \pm 0.6$ & $4.3 \pm 0.7$ & $4.1 \pm 0.7$ & $4.3 \pm 0.6$ & \\
\hline LV end diastolic volume $\left(\mathrm{mL}, \mathrm{mL} / \mathrm{m}^{2}\right)$ & $98 \pm 30$ & $95 \pm 27$ & $82 \pm 23$ & $94 \pm 29$ & $49 \pm 11$ \\
\hline LV stroke volume $(\mathrm{mL})$ & $60 \pm 18$ & $59 \pm 16$ & $50 \pm 14$ & $58 \pm 17$ & $30 \pm 8$ \\
\hline LV ejection fraction (\%) & $62 \pm 6$ & $63 \pm 6$ & $62 \pm 5$ & $62 \pm 6$ & \\
\hline LV mass $\left(g, g / m^{2}\right)$ & $126 \pm 37$ & $146 \pm 61$ & $133 \pm 50$ & $132 \pm 47$ & $70 \pm 19$ \\
\hline $\begin{array}{l}\text { Concentric LV hypertrophy } \\
\text { (RWT>0.42) }\end{array}$ & $8(19 \%)$ & $5(25 \%)$ & $2(20 \%)$ & $15(21 \%)$ & \\
\hline Pre-A wave $\mathrm{LA}$ volume $\left(\mathrm{mL}, \mathrm{mL} / \mathrm{m}^{2}\right)$ & $38 \pm 15^{*}$ & $55 \pm 17$ & $53 \pm 11$ & $45 \pm 17$ & $24 \pm 9$ \\
\hline Minimum LA volume $\left(\mathrm{mL}, \mathrm{mL} / \mathrm{m}^{2}\right)$ & $23 \pm 9^{*}$ & $47 \pm 16$ & $30 \pm 7$ & $28 \pm 12$ & $15 \pm 6$ \\
\hline $\mathrm{S}^{\prime}$ right ventricle free wall $(\mathrm{cm} / \mathrm{s})$ & $11 \pm 2$ & $12 \pm 3$ & $11 \pm 3$ & $12 \pm 3$ & \\
\hline Peak E-wave (cm/s) & $63 \pm 16$ & $66 \pm 19$ & $73 \pm 18$ & $67 \pm 17$ & \\
\hline Peak A-wave $(\mathrm{cm} / \mathrm{s})$ & $56 \pm 20 \dagger$ & $70 \pm 24$ & $74 \pm 17$ & $65 \pm 22$ & \\
\hline E/A ratio & $1.2 \pm 0.5$ & $1.1 \pm 0.6$ & $1.0 \pm 0.3$ & $1.2 \pm 0.5$ & \\
\hline E-wave deceleration time (ms) & $194 \pm 58$ & $233 \pm 70$ & $220 \pm 60$ & $216 \pm 62$ & \\
\hline
\end{tabular}

${ }^{*} \mathrm{P}<0.01$ normal versus abnormal or/and indeterminate LV diastolic function.

$\dagger P<0.05$ normal versus abnormal and/or indeterminate LV diastolic function.

DD, diastolic dysfunction; LA, left atrium; LV, left ventricle; RWT, relative wall thickness (>0.42 concentric).

two observers was $-3.6 \pm 2 \mathrm{SD} 7.6 \mathrm{~mL}(95 \%$ limits of agreement). This represents on average $4 \% \pm 7 \%$ of the LA volume differences between two independent observers. The mean difference between manually traced and automated LA volume was $0 \pm 2 \mathrm{SD} 3.8 \mathrm{~mL}$. This represents on average $0 \% \pm 5 \%$ of the $\mathrm{LA}$ volume difference between the manual and automated measurements.

\section{DISCUSSION}

This study provides several observations on LA and LV volume measurements obtained from prospectively triggered CTCA. It also provides a new observation illustrating the potential role of CTCA in the assessment of LVDD. Since the word diastole, originally derived from Greek, means 'dilatation or expansion', DE and DEF were chosen as terms to represent new indices of interest measured in the study.

The main findings of this study are summarised as follows:

1. In agreement with others, CTCA derived volumes of both the LV and the LA correlated well with TTE measurements but were larger compared with those obtained from TTE. ${ }^{7-14}$ CTCA derived LV volume measured in diastasis was on average $37 \% \pm 20 \%$ bigger than that measured from TTE. CTCA derived LA diastolic volume correlated well with all TTE derived diastolic LA volumes, with the closest correlation being both maximum LA volume and LA pre-A volume. The average percentage of difference between CTCA- LA volume and TTE maximum LA volume was $11 \% \pm 21 \%$. The observed differences in measurements between TTE and CTCA reflect a difference in protocol of image acquisition. In prospectively triggered CTCA protocol, in order to reduce the amount of radiation, a selected phase of a cardiac cycle is acquired. Since CTCA is becoming almost a 'bedside' test in patients with chest pain assessment and intermediate pretest probability, ${ }^{1-4}$ we aimed to record the trend in differences in volume measurements between TTE and CTCA. We did not attempt to use the prediction model of LVEDV developed by Khatri et al ${ }^{14}$ who proposed a mathematic method of LV end-diastolic volume estimation from prospectively gated CTCA. As volume assessment was not our main aim we did not focus on 


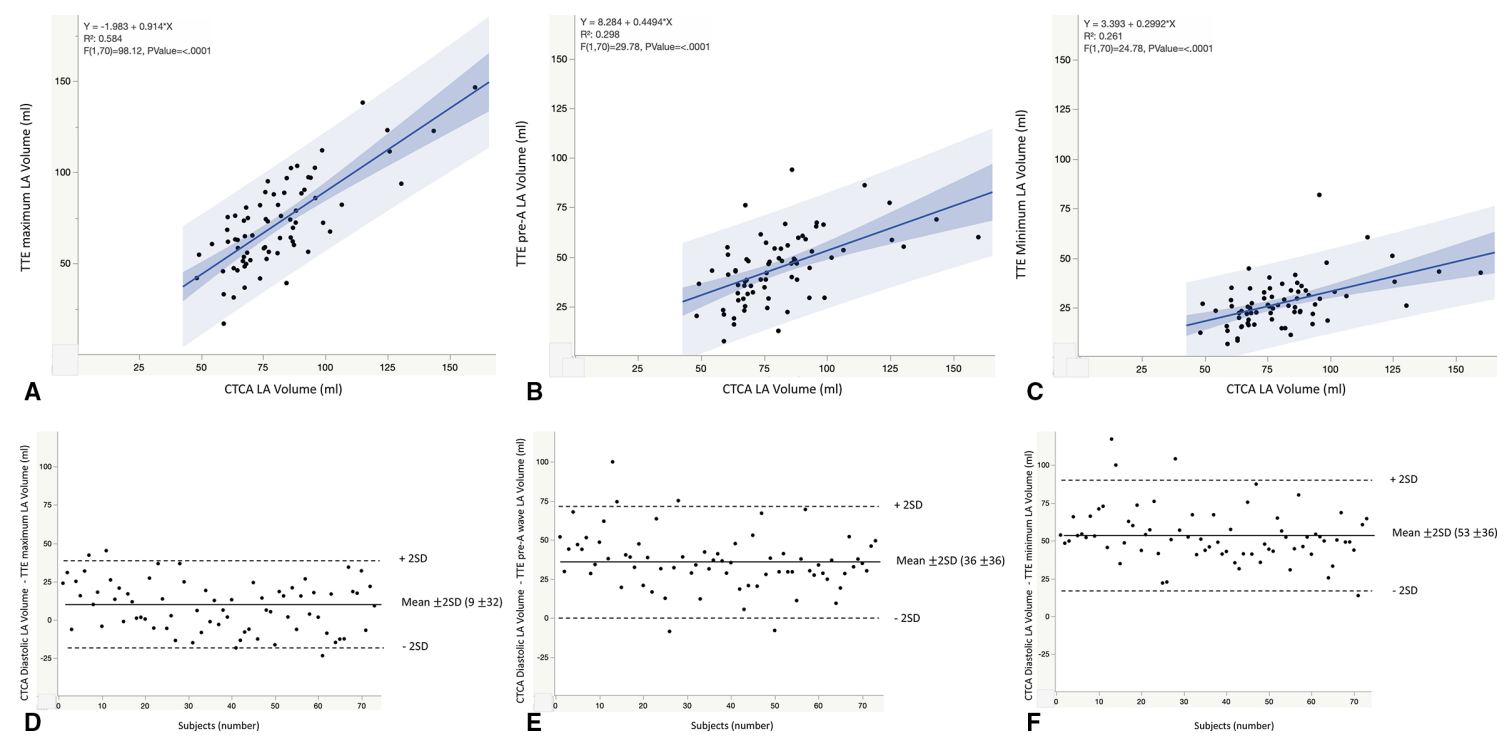

Figure 3 (A) Linear correlation between CTCA diastolic LA volume and TTE maximum LA volume. (B) Linear correlation between CTCA diastolic LA volume and TTE pre-A LA volume. (C) Linear correlation between CTCA diastolic LA volume and TTE minimum LA volume. (D) Bland and Altman plot. Differences between CTCA diastolic LA volume and TTE maximum LA volume. (E). Bland and Altman plot. Differences between CTCA diastolic LA volume and TTE pre-A LA volume. (F) Bland and Altman plot. Differences between CTCA diastolic LA volume and TTE minimum LA volume. CTCA, CT coronary angiography; LA, left atrium; TTE, transthoracic echocardiogram.

Table 4 Transthoracic echocardiogram (TTE) left atrial (LA) function analysis and CT coronary angiography (CTCA) derived indices

\begin{tabular}{|c|c|c|c|c|c|}
\hline \multirow[b]{3}{*}{ Mean \pm SD } & \multicolumn{4}{|l|}{ TTE } & \multirow[b]{3}{*}{ СТCA } \\
\hline & \multicolumn{3}{|c|}{ LV diastolic function } & \multirow[b]{2}{*}{ All } & \\
\hline & Normal & Abnormal & Indeterminate & & \\
\hline Diastolic expansion (DE) & & & & & $1.62 \pm 0.43$ \\
\hline Diastolic expansion fraction (DEF) & & & & & $34 \pm 16$ \\
\hline \multicolumn{6}{|l|}{ LA pump (booster) function } \\
\hline LA active emptying volume & $14 \pm 8^{\star \star}$ & $20 \pm 13$ & $21 \pm 7$ & $17 \pm 10^{\star} \dagger$ & \\
\hline LA active emptying fraction & $0.36 \pm 0.14$ & $0.36 \pm 0.19$ & $0.40 \pm 0.10$ & $0.37 \pm 0.15$ & \\
\hline \multicolumn{6}{|l|}{ LA conduit function } \\
\hline LA passive emptying & $29 \pm 16$ & $25 \pm 16$ & $24 \pm 12$ & $27 \pm 16$ & \\
\hline Volume LA passive emptying fraction & $0.43 \pm 0.14^{\star *}$ & $0.29 \pm 0.17$ & $0.30 \pm 0.11$ & $0.30 \pm 0.16 \neq \S$ & \\
\hline \multicolumn{6}{|l|}{ Conduit } \\
\hline Volume & $17 \pm 18$ & $14 \pm 17$ & $3 \pm 17$ & $3 \pm 17$ & \\
\hline Ratio & $1.6 \pm 0.8^{\star \star}$ & $1.5 \pm 0.8$ & $1.0 \pm 0.3$ & $1.5 \pm 0.8 * \S$ & \\
\hline \multicolumn{6}{|l|}{ LA reservoir function } \\
\hline LA total emptying volume & $43 \pm 19$ & $45 \pm 19$ & $16 \pm 19$ & $44 \pm 18$ & \\
\hline LA total emptying fraction & $0.64 \pm 0.10$ & $0.56 \pm 0.13$ & $0.59 \pm 0.09$ & $0.61 \pm 0.12^{\star} \S$ & \\
\hline LA expansion index & $66 \pm 25^{\star \star}$ & $79 \pm 25$ & $79 \pm 18$ & $71 \pm 25 \S \rrbracket$ & \\
\hline
\end{tabular}

${ }^{*} \mathrm{P}<0.01$ (TTE LA function measurements vs CTCA DE).

$\dagger \mathrm{P}<0.0001$ (TTE LA function measurements vs CTCA DEF).

$\ddagger \mathrm{P}<0.05$ (TTE LA function measurements vs CTCA DE).

$\S \mathrm{P}<0.01$ (TTE LA function measurements vs CTCA DEF).

१P $<0.05$ (TTE LA function measurements vs CTCA DEF).

${ }^{* *} \mathrm{P}<0.05$ (normal vs abnormal or indeterminate LV diastolic function). 
Table 5 Comparison between normal and elevated and/or indeterminate left ventricle (LV) filling pressure and CT coronary angiography (CTCA) derived diastolic indices

\begin{tabular}{|c|c|c|c|c|}
\hline \multirow{2}{*}{$\begin{array}{l}\text { CTCA data } \\
\text { (Mean } \pm \text { SD) }\end{array}$} & \multicolumn{3}{|c|}{ LV diastolic dysfunction } & \multirow[b]{2}{*}{$P$ value } \\
\hline & Normal & Abnormal & Indeterminate & \\
\hline LV diastolic volume $(\mathrm{mL})$ & $136 \pm 37$ & $122 \pm 32$ & $114 \pm 23$ & $<0.01$ \\
\hline LA diastolic volume (mL) & $77 \pm 20$ & $86 \pm 25$ & $84 \pm 13$ & $<0.05$ \\
\hline LA diastolic volume index $\left(\mathrm{mL} / \mathrm{m}^{2}\right)$ & $40 \pm 8$ & $46 \pm 11$ & $48 \pm 6$ & $<0.01$ \\
\hline
\end{tabular}

this topic further. However, our results are similar to those by Khatri et al.

2. CTCA derived DE and DEF correlated with LA active emptying volume, LA passive emptying fraction, conduit ratio and both total emptying fraction and LA expansion index.

3. Patients with normal LV diastolic function, as opposed to either indeterminate or abnormal LV diastolic function, showed bigger values in the following parameters: LV diastolic volumes, LA volume indices, DE and

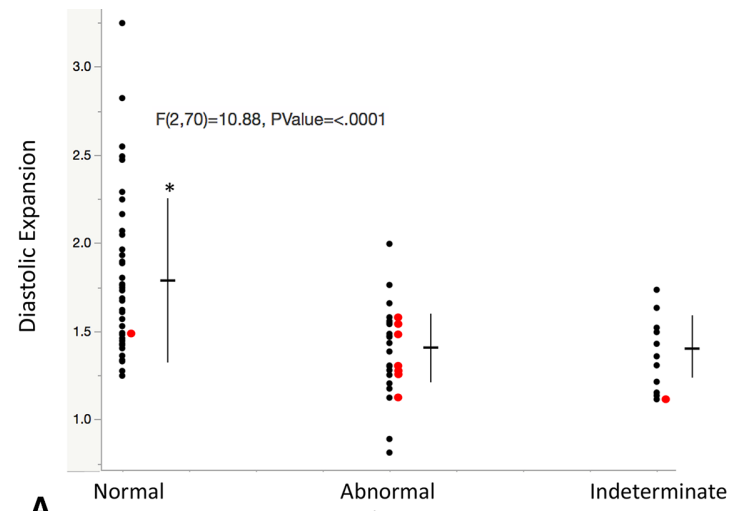

A LV Diastolic Function

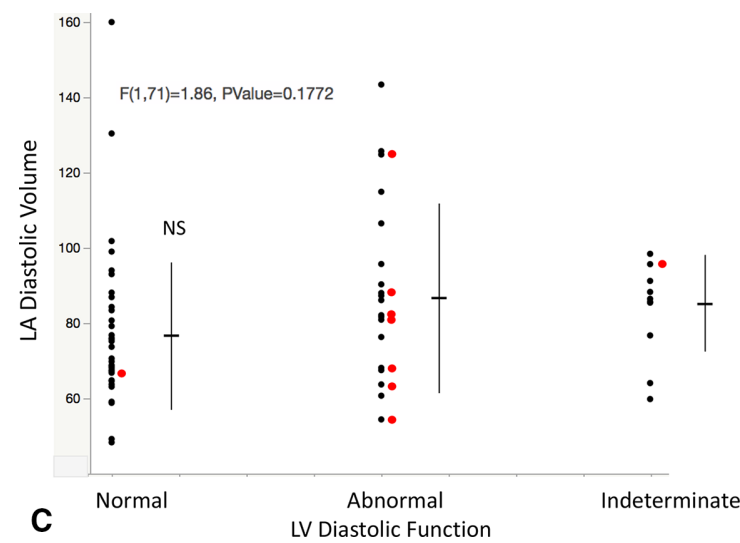

DEF. However, only the DE allowed to differentiate normal from either abnormal or indeterminate LV diastolic functions with good accuracy. The DE value above 1.65 was indicative of a normal LV diastolic function, while a value below 1.4 was indicative of either abnormal and/or indeterminate LV diastolic function. It appears that $\mathrm{DE}$ holds a promise to be a reliable parameter that may be easily calculated from information available from conventional diastolic CTCA scans.
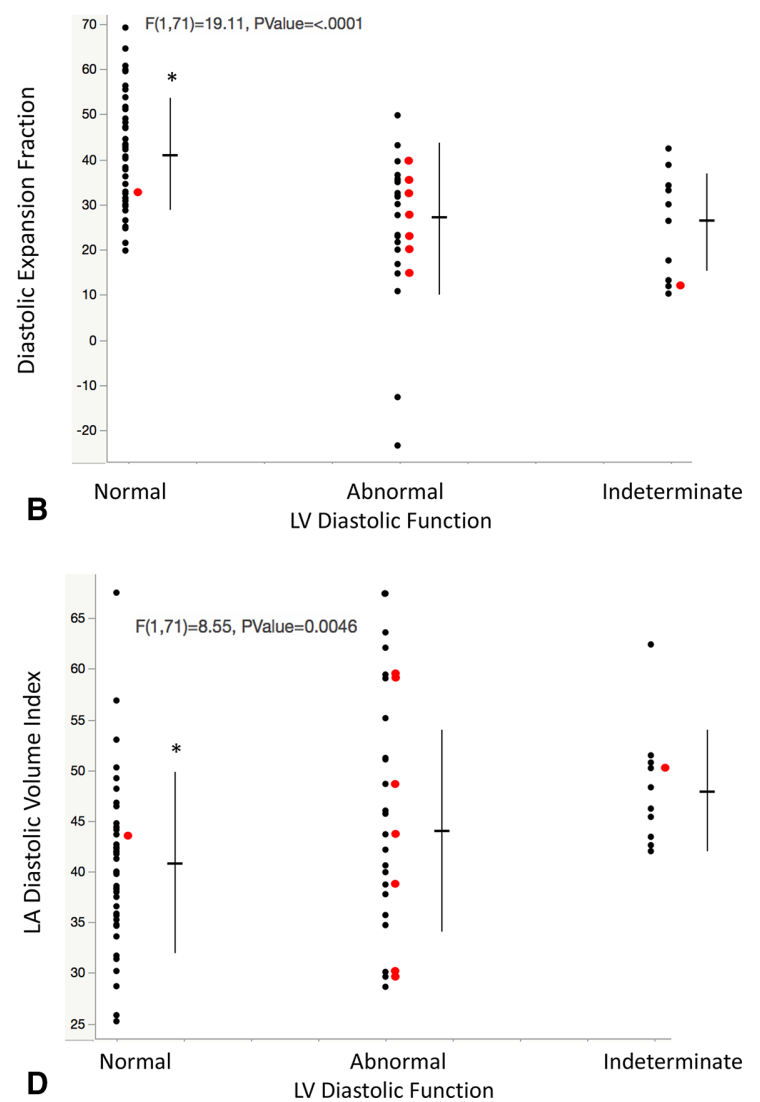

Figure 4 (A) Comparison between CT coronary angiography (CTCA) derived diastolic expansion (DE) and transthoracic echocardiography (TTE) assessed LV diastolic dysfunction (DD). (B) Comparison between CTCA derived DE fraction (DEF) and TTE assessed LV DD. (C) Comparison between CTCA derived diastolic LA volume and TTE assessed LV DD. (D) Comparison between CTCA derived diastolic LA volume index and TTE assessed LV DD. Red dots indicate the patients with documented elevated LV filling pressure by cardiac catheterisation. DE is calculated as a ratio (LV volume $\div$ LA volume) measured during diastasis and acquired by CTCA. DD is assessed by TTE according to American Society of Echocardiography/European Association of Cardiovascular Imagingrecommendations. DEF is calculated as a $\{[(\mathrm{LV}$ volume-LA volume $) \div \mathrm{LV}$ volume $] \times 100\}$ measured during diastasis and acquired by CTCA. LA, left atrial; LV, left ventricle. 
Table 6 The contribution of parameters on diastolic expansion (DE) and diastolic expansion fraction (DEF) indices by multiple regression analysis

\begin{tabular}{llllll}
\hline & DE & & DEF & \\
\cline { 2 - 3 } \cline { 5 - 6 } & $\begin{array}{l}\text { Log } \\
\text { worth }\end{array}$ & P value & $\begin{array}{l}\text { Log } \\
\text { worth }\end{array}$ & P value \\
\hline Age $^{*}$ & 3.384 & 0.0004 & & 1.799 & 0.0159 \\
\hline LV diastolic dysfunction $^{*}$ & 2.409 & 0.0039 & 2.424 & 0.0038 \\
\hline $\begin{array}{l}\text { Heart rate difference } \\
\text { (between TTE and CTCA) }\end{array}$ & 0.544 & 0.2856 & 0.751 & 0.1778 \\
\hline LV ejection fraction & 0.212 & 0.6132 & 0.258 & 0.5518 \\
$\begin{array}{l}\text { Time difference } \\
\text { (between TTE and CTCA) }\end{array}$ & 0.212 & 0.6152 & 0.279 & 0.5256 \\
\hline LV stroke volume & 0.016 & 0.9630 & 0.113 & 0.7704 \\
\hline LV end diastolic volume & 0.007 & 0.9850 & 0.084 & 0.8250 \\
\hline
\end{tabular}

*Statistically significant.

CTCA, CT coronary angiography; LV, left ventricle; TTE, transthoracic echocardiogram.

The question is: why should we be interested in measuring LVDD from CTCA data since both TTE and cardiac MRI ${ }^{25-28}$ are well recognised and widely available techniques that already do this well? Achenbach et $a t^{29}$ posed such a question in their editor's page for the Journal of the American College of Cardiology Cardiovascular Imaging entitled 'Climbing Mount Everest "Because It's There"' in response to Boogers et al paper on feasibility of LVDD assessment with cardiac CT. ${ }^{15}$ It was then agreed that additional information on DD may add to the growing list on noncoronary applications of cardiac CT. Such incremental prognostic value indices may potentially translate into more relevant information and as a result improve the management and the prognosis.

Thus far, LVDD was assessed in protocols where retrospective gating was used resulting in the acquisition of the entire cardiac cycle data and higher radiation dose. ${ }^{12-14}$ However, our study is the first to look at the feasibility of CTCA with prospective ECG triggering in the assessment of LVDD.

LA to LV ratio was measured in 2007 by Germans et $a l$, in a group of healthy volunteers using cardiac MRI. ${ }^{30}$ Their reported ratios of LA to LV volumes were increasing with age. A similar concept was applied by Takeuchi et $a l^{31}$ where $\mathrm{LV}$ to $\mathrm{LA}$ ratio (the reversed ratio as compared with Germans et al) was measured using three-dimensional echocardiography and once again showing a similar change with age. ${ }^{31}$ The authors suggested that this observation might be useful to elucidate abnormal LV to LA coupling in patients with heart failure. ${ }^{30}{ }^{31}$ In the current study, both LVDD and increasing age lowered DE, but the contribution of those factors was independent. As DE can be obtained easily and with excellent reproducibility during a routine prospectively gated CTCA, it's prognostic value may become useful in risk stratification by identifying characteristics that can predict future adverse events, and to guide primary or secondary prevention.

Table 7 Accuracy of CT coronary angiography derived diastolic expansion to differentiate presence of normal vs (A) abnormal, (B) indeterminate or (C) either abnormal or indeterminate left ventricle diastolic function

\begin{tabular}{|c|c|c|c|c|}
\hline DE & Sensitivity (\%) & Specificity (\%) & $\begin{array}{l}\text { Positive predicted } \\
\text { value }\end{array}$ & $\begin{array}{l}\text { Negative } \\
\text { predicted value }\end{array}$ \\
\hline \multicolumn{5}{|l|}{ (A) } \\
\hline $95 \% \mathrm{Cl}$ & 0.38 to 0.69 & 0.69 to 1.01 & 0.75 to 1.01 & 0.31 to 0.64 \\
\hline 1.40-1.65 ('grey zone') & $\mathrm{n} / \mathrm{a}$ & $\mathrm{n} / \mathrm{a}$ & $\mathrm{n} / \mathrm{a}$ & $\mathrm{n} / \mathrm{a}$ \\
\hline $95 \% \mathrm{Cl}$ & 0.21 to 0.67 & 0.78 to 0.98 & 0.35 to 0.88 & 0.66 to 0.90 \\
\hline \multicolumn{5}{|l|}{ (B) } \\
\hline$>1.65$ (normal diastolic function) & 54 & 91 & 96 & 34 \\
\hline $95 \% \mathrm{Cl}$ & 0.38 to 0.69 & 0.76 to 1.07 & 0.87 to 1.04 & 0.19 to 0.54 \\
\hline \multicolumn{5}{|l|}{ (C) } \\
\hline$>1.65$ (normal diastolic function) & 54 & 87 & 85 & 59 \\
\hline $95 \% \mathrm{Cl}$ & 0.38 to 0.69 & 0.76 to 0.99 & 0.71 to 0.98 & 0.46 to 0.74 \\
\hline 1.40-1.65 ('grey zone') & $\mathrm{n} / \mathrm{a}$ & $\mathrm{n} / \mathrm{a}$ & $\mathrm{n} / \mathrm{a}$ & $\mathrm{n} / \mathrm{a}$ \\
\hline $\begin{array}{l}<1.40 \text { (abnormal or } \\
\text { indeterminate diastolic function) }\end{array}$ & 48 & 88 & 75 & 69 \\
\hline $95 \% \mathrm{Cl}$ & 0.32 to 0.67 & 0.78 to 0.98 & 0.58 to 0.95 & 0.57 to 0.82 \\
\hline
\end{tabular}




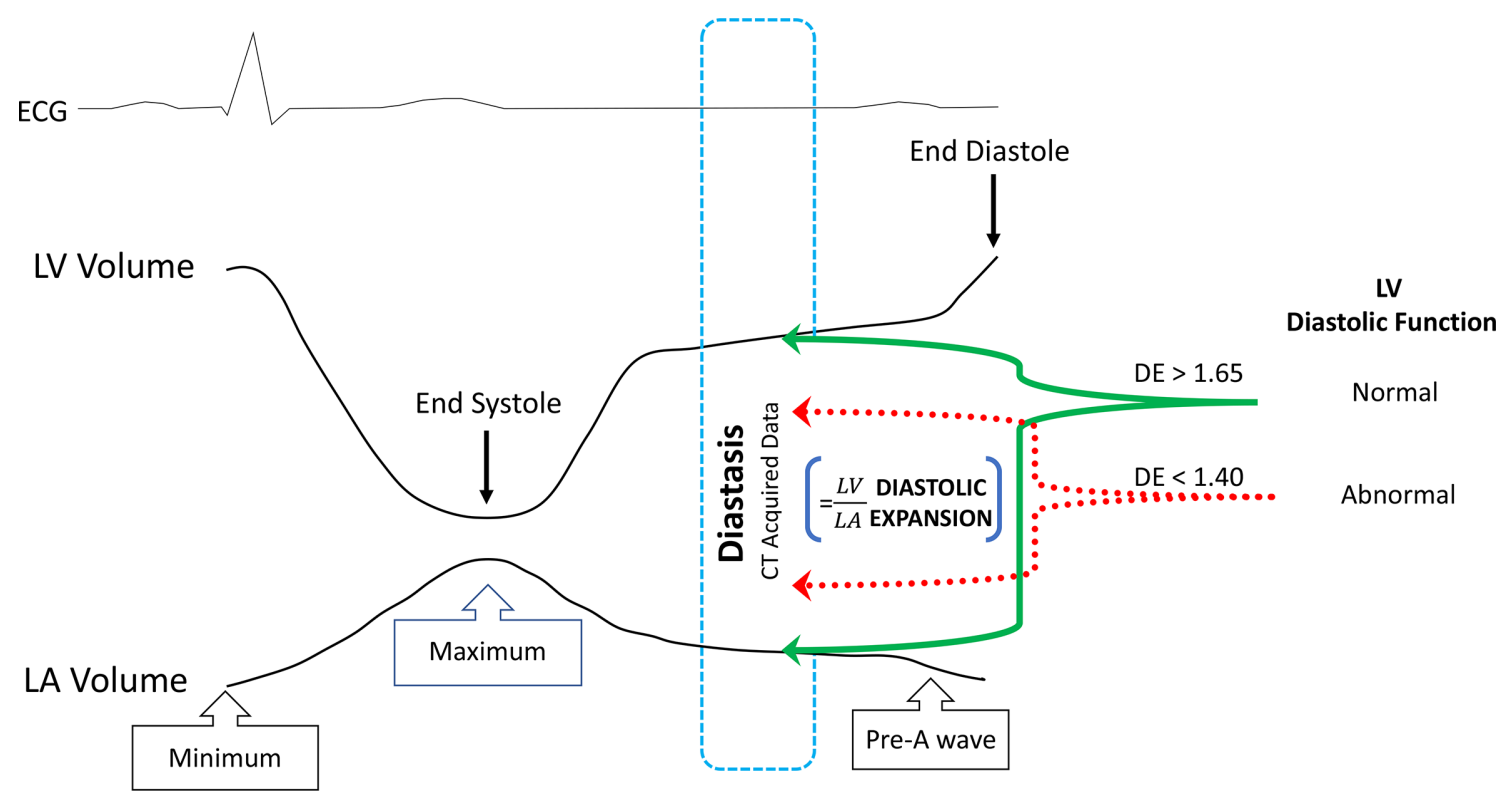

Figure 5 Schematic diagram illustrating the principle of diastolic expansion (DE) index derived from CT coronary angiography. LA, left atrial; LV, left ventricle.

\section{CONCLUSIONS}

This new study establishes the potential clinical value of CTCA LV and LA volume measurements, which were taken during diastasis in the assessment of LVDD. Both $\mathrm{DE}$ and DEF can be obtained easily and with excellent reproducibility during a routine prospectively triggered CTCA study. The DE value above 1.65 was indicative of normal LV diastolic function, while a value below 1.4 was indicative of either abnormal and/or intermediate LV diastolic function (figure 5). This added information may assist in the early detection of subclinical diseases, and may also refine risk stratification in patients undergoing CTCA. A larger group of patients will need to be studied to further strengthen the reliability of our results on the role of DE in the assessment of LVDD.

\section{Limitations}

This is a retrospective designed study with a relatively long time difference between CTCA and TTE. Despite this limitation, all our patients were clinically stable with preserved LVEF $\geq 50 \%$, and there were no changes in medications between these two tests. Therefore, the potential effect of pre-load and after-load was minimal.

Additionally, none of our patients were on loop diuretics. In order to minimise other factors on the LV diastolic function, patients with atrial fibrillation, permanent pacemakers, and significant valvular pathology were excluded. A small group of patients needed to be excluded due to higher heart rate during image acquisition, which resulted in a systolic scan. Only a small group of patients underwent invasive cardiac catheterisation and/or subsequent coronary artery revascularisation. Although the results from this subgroup were in concordance with the main results, more invasive data would add further value to the manuscript.
Acknowledgements We would like to thank Professor Robert Ware from the Griffith University, Queensland for his critical comments and statistical advice.

Contributors AL, the corresponding author, is responsible for the conception and design of the study, along with the interpretation of the data. PP is responsible for the collection and analysis of the data, and the interpretation of the data. JS and $\mathrm{HH}$ are responsible for the analysis of CT data. All authors took part in drafting the manuscript and $A L$ and PP took part in revising the manuscript critically for important intellectual content.

Funding This project was supported by Wesley Medical Research Clinical Research Grant \#2020-23.

Disclaimer All authors report that they have no relationship with the industry to be disclosed.

Competing interests None declared.

Patient consent for publication Not required.

Ethics approval The Institutional Ethical Committee approved the retrospective use of clinical data and informed written consent was obtained from all patients.

Provenance and peer review Not commissioned; externally peer reviewed.

Data availability statement Data are available upon reasonable request.

Open access This is an open access article distributed in accordance with the Creative Commons Attribution Non Commercial (CC BY-NC 4.0) license, which permits others to distribute, remix, adapt, build upon this work non-commercially, and license their derivative works on different terms, provided the original work is properly cited, appropriate credit is given, any changes made indicated, and the use is non-commercial. See: http://creativecommons.org/licenses/by-nc/4.0/.

ORCID iD

Aleksandra Lange http://orcid.org/0000-0003-3556-1214

\section{REFERENCES}

1 Lubbers M, Dedic A, Coenen A, et al. Calcium imaging and selective computed tomography angiography in comparison to functional testing for suspected coronary artery disease: the multicentre, randomized crescent trial. Eur Heart J 2016;37:1232-43.

2 Knuuti J, Wijns W, Saraste A. Esc guidelines for the diagnosis and management of chronic coronary syndromes. The task force for the diagnosis and management of chronic coronary syndromes of the European Society of cardiology (ESC). Eur Heart $J$ 2019;2020:407-77.

3 Haase R, Schlattmann P, Gueret P, et al. Diagnosis of obstructive coronary artery disease using computed tomography angiography in 
patients with stable chest pain depending on clinical probability and in clinically important subgroups: meta-analysis of individual patient data. BMJ 2019;365:11945.

4 Newby DE, Adamson PD, Berry C. For the SCOT-HEART Investigators. coronary $\mathrm{CT}$ angiography and 5-year risk myocardial infarction. N Engl J Med 2018;379:924-33.

5 Schlattmann P, Schuetz GM, Dewey M. Influence of coronary artery disease prevalence on predictive values of coronary CT angiography: a meta-regression analysis. Eur Radiol 2011;21:1904-13.

6 Dewey M, Rief M, Martus P, et al. Evaluation of computed tomography in patients with atypical angina or chest pain clinically referred for invasive coronary angiography: randomised controlled trial. BMJ 2016;355:i5441.

7 Miyasaka $\mathrm{Y}$, Tsujimoto $\mathrm{S}$, Maeba $\mathrm{H}$, et al. Left atrial volume by realtime three-dimensional echocardiography: validation by 64-slice multidetector computed tomography. J Am Soc Echocardiogr 2011;24:680-6.

8 ACY To, Flamm SD, Marwick TH, et al. Clinical utility of multimodality LA imaging: assessment of size, function, and structure. J Am Coll Cardiol Img 2011:4:788-98

9 Arsanjani R, Flint N, Beigel R, et al. Comparison of accuracy of left atrial area and volume by two-dimensional trans-thoracic echocardiography versus computed tomography. Am J Cardiol 2019;123:1180-4.

10 Koka AR, Yau J, Van Why C, et al. Underestimation of left atrial size measured with transthoracic echocardiography compared with 3D MDCT. AJR Am J Roentgenol 2010;194:W375-81.

11 Wen Z, Zhang Z, Yu W, et al. Assessing the left atrial phasic volume and function with dual-source CT: comparison with $3 \mathrm{~T}$ MRI. Int $J$ Cardiovasc Imaging 2010;26 Suppl 1:83-92.

12 Rizvi A, Deaño RC, Bachman DP. Analysis of ventricular function by computed tomography. J Cardiovasc Comput Tomogr 2015;9:1-12.

13 Boczar KE, Alam M, Chow BJW, et al. Incremental prognostic value of estimated LV end-diastolic volume by cardiac CT. JACC Cardiovasc Imaging 2014;7:1280-1.

14 Khatri PJ, Tandon V, Chen L, et al. Can left ventricular end-diastolic volumes be estimated with prospective ECG-gated CT coronary angiography? Eur J Radiol 2012;81:226-9.

15 Boogers MJ, van Werkhoven JM, Schuijf JD, et al. Feasibility of diastolic function assessment with cardiac CT: feasibility study in comparison with tissue Doppler imaging. JACC Cardiovasc Imaging 2011:4:246-56.

16 Wen Z, Ma H, Zhao Y, et al. Left ventricular diastolic dysfunction assessment with dual-source CT. PLoS One 2015;10:e0127289.

17 Hwang J-S, Lee H, Lee B, et al. Estimation of diastolic filling pressure with cardiac $\mathrm{CT}$ in comparison with echocardiography using tissue Doppler imaging: determination of optimal CT reconstruction parameters. Korean J Radiol 2017; 18:632-42.

18 Menke J, Unterberg-Buchwald C, Staab W, et al. Head-To-Head comparison of prospectively triggered vs retrospectively gated coronary computed tomography angiography: meta-analysis of diagnostic accuracy, image quality, and radiation dose. Am Heart $J$ 2013;165:154-63.

19 Sun Z, Ng K-H. Prospective versus retrospective ECG-gated multislice CT coronary angiography: a systematic review of radiation dose and diagnostic accuracy. Eur $\mathrm{J}$ Radiol 2012;81:e94-100.

20 Lang RM, Badano LP, Mor-Avi V, et al. Recommendations for cardiac chamber quantification by echocardiography in adults: an update from the American Society of echocardiography and the European association of cardiovascular imaging. J Am Soc Echocardiogr 2015;28:1-39.

21 Nagueh SF, Smiseth OA, Appleton CP, et al. Recommendations for the evaluation of left ventricular diastolic function by echocardiography: an update from the American Society of echocardiography and the European association of cardiovascular imaging. Eur Heart J Cardiovasc Imaging 2016;17:1321-60.

22 Ommen SR, Nishimura RA, Appleton CP, et al. Clinical utility of Doppler echocardiography and tissue Doppler imaging in the estimation of left ventricular filling pressures: a comparative simultaneous Doppler-catheterization study. Circulation 2000;102:1788-94

23 Blume GG, Mcleod CJ, Barnes ME, et al. Left atrial function: physiology, assessment, and clinical implications. Eur J Echocardiogr 2011;12:421-30.

24 Thomas L, Marwick TH, Popescu BA, et al. Left atrial structure and function, and left ventricular diastolic dysfunction: JACC state-ofthe-art review. J Am Coll Cardiol 2019;73:1961-77.

25 Chambers J, Fuat A, Liddiard S. Community echocardiography for heart failure. A consensus statement from representatives of the British Society of echocardiography, the British heart failure Society, the coronary heart disease collaborative and the primary care cardiovascular Society. Brit J Cardiol 2004;11:399-402.

26 Cheesman MG, Leech G, Chambers J, et al. Central role of echocardiography in the diagnosis and assessment of heart failure. Heart 1998;80:1S-5.

27 Kraigher-Krainer E, Shah AM, Gupta DK, et al. Impaired systolic function by strain imaging in heart failure with preserved ejection fraction. J Am Coll Cardiol 2014;63:447-56.

28 Habibi M, Chahal H, Opdahl A, et al. Association of CMR-measured La function with heart failure development: results from the MESA study. JACC Cardiovasc Imaging 2014;7:570-9.

29 Achenbach S, Narula J. Climbing Mount Everest "Because It's There!". JACC Cardiovasc Imaging 2011;4:311-3.

30 Germans T, Götte MJW, Nijveldt R, et al. Effects of aging on left atrioventricular coupling and left ventricular filling assessed using cardiac magnetic resonance imaging in healthy subjects. Am J Cardiol 2007:100:122-7.

31 Takeuchi M, Kitano T, Nabeshima Y, et al. Left ventricular and left atrial volume ratio assessed by three-dimensional echocardiography: novel indices for evaluating age-related change in left heart chamber size. Physiol Rep 2019;7:e14300. 